\title{
CHARGING SYSTEM ANALYSIS IN STATIC AND DYNAMIC WIRELESS ELECTRIC VEHICLE
}

\author{
Sankalp Bhatnagar \\ Department of Mechanical Engineering \\ Government Engineering College, Ajmer, Rajasthan, India \\ Shubham Parihar, Rohan Nathiya and Nikhil Mundra \\ Department of Mechanical Engineering \\ Government Engineering College, Ajmer, Rajasthan, India
}

\begin{abstract}
Depletion in rising fuel prices and green-house gas emissions can be aided by electrified transportation. This evolution urges an installation of diversified charging networks, in an adaptable environment, to be successful. Wireless electric vehicle charging systems (WEVCS) can be a probable substitute technology to charge the EVS without any plug-in complications. In this paper, the present-day available wireless power transmit technology for electric vehicle is examined. And explanation of two prime applications of WEVCs and record of their progress with up-to-date features from universities, research laboratories are examined and presented. Moreover, the futuristic WEVCS; in-wheel and vehicle-to-grid WCS are compared with the existing ones.

Keywords: Finite Element Method, Wireless electric vehicle charging system, Electric vehicles, Wireless power transmit, Electromagnetic compatibility.

Cite this Article: Sankalp Bhatnagar, Shubham Parihar, Rohan Nathiya and Nikhil Mundra, Charging System Analysis in Static and Dynamic Wireless Electric Vehicle, International Journal of Advanced Research in Engineering and Technology, 10(1), 2019, pp 104-120.

http://iaeme.com/Home/issue/IJARET?Volume=10\&Issue $=1$
\end{abstract}

\section{INTRODUCTION}

In high power applications, inclusive of electric vehicles [1] and plug in EV's [2] wireless charging systems are being propounded nowadays. Dependability, simpleness, and adaptability in WCS has an upper hand over plug-in charging system. The restrain connected with wireless charging system is that they can only be employed when the vehicle is in motionless state. Moreover, immobile WCS have few challenges; electromagnetic compatibility issues, bulky structures issues, restricted power transfer, and shorter range. In pursuance of refining the two areas of range and adequate volume of battery storage, dynamic mode of operation of the WCS for electric vehicles has been researched [3]. This method permits charging of battery storage 
devices while the vehicle is in motion. Although, a dynamic WCS must cross two vital barriers, coil misalignment and large air gap, prior to be accepted globally. The factors on which the power transfer efficiency depends are, the air gap distance in between the source and receiver, and coil alignment. For larger vehicles, the average air gap distance is greater than $300 \mathrm{~mm}$, while it may be in between 150 and $300 \mathrm{~mm}$ for smaller vehicles. Furthermore, various distinctive compensation methods are employed to lessen parasitic losses and ameliorate system efficiency [4-5]. In this review paper, the rudimentary operation of WCS for electric vehicles, including methods of power transmit, is analyzed. Additionally, diversified structures of wireless transformer are explained in order to revamp power transmit efficiency. Current developments in both commercial sectors and universities in the static and dynamic modes of WEVCS are also covered in this paper.

\section{WIRELESS CHARGING SYSTEM FOR ELECTRIC VEHICLES}

\subsection{Basic principle}

The block diagram of static WCS is demonstrated in figure 1. Through AC/DC and DC/AC converters, the $\mathrm{AC}$ mains from the grid is converted into high frequency AC to qualify power transfer from the transmission coil to the receiving coil. For to ameliorate total system efficiency, series and parallel amalgamations-based compensation topology are connected on both the transmitting and receiving sides [6-7]. The oscillating magnetic flux fields are converted into high frequency AC through the receiving coil which is mounted underneath the vehicle. Then, the high frequency AC is converted into a stable DC supply which further gets utilized by on-board batteries. Further, to avoid any health and safety issues a battery management system (BMS), communications and power control are incorporated to ensure stable operation. Moreover, magnetic planar ferrite plates are introduced at both the transmitter and receiver sides, to lessen any harmful leakage fluxes and to enhance magnetic flux distribution.

\subsection{Wireless power transfer techniques}

Ever since the inception of wireless charging systems for electric vehicles, four techniques for the design of WEVCS have been employed:

a) Magnetic gear wireless power transfer (MGWPT)

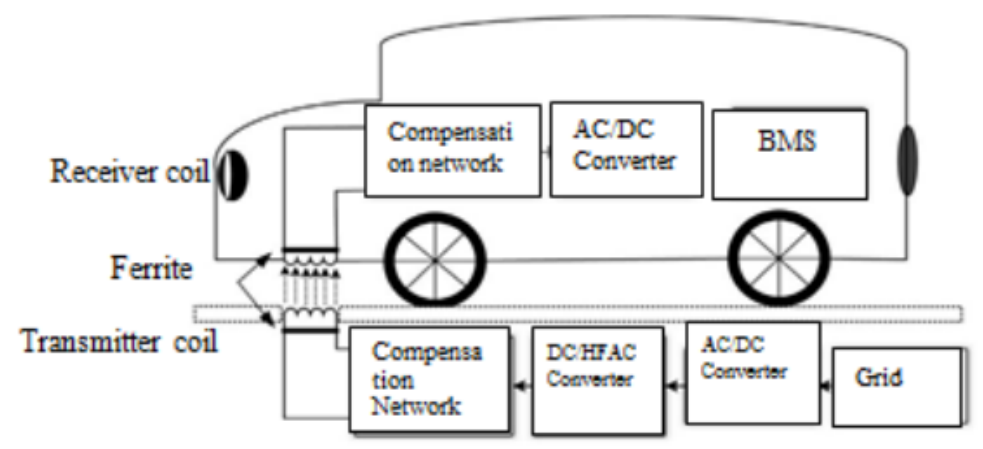

Figure 1 Block diagram of static WCS

b) Capacitive wireless power transfer (CWPT)

c) Inductive wireless power transfer (IWPT)

d) Resonant inductive power transfer (RIPT) 


\subsubsection{Magnetic gear wireless power transfer}

MGWPT is comparatively unalike to both the CWPT and IWPT, as displayed in figure 2. In this technique, the two synchronized permanent magnets are placed beside each other unlike other coaxial cable based WEVCS. To generate a mechanical torque on the primary permanent magnet a current source is applied to the transmitter winding, the main power being the current source. By using this mechanical torque, the primary magnet rotates and induces a torque onto the secondary permanent magnet. So, the primary permanent magnet works as the generator and the secondary permanent magnet receives power and delivers it to the battery through BMS [8]. A sample model of MGWPT was produced and have the capability of supplying $150 \mathrm{~mm}$ air gap distance. Although, this method has numerous challenges linked with incorporating the tech into static and dynamic applications. As the coupling between the two permanent magnets decreases unexpectedly, the axis to axis separation is inversely proportional to the power transfer capability. As an outcome, it could be viable for static WEVCS but significantly challenging for dynamic applications.

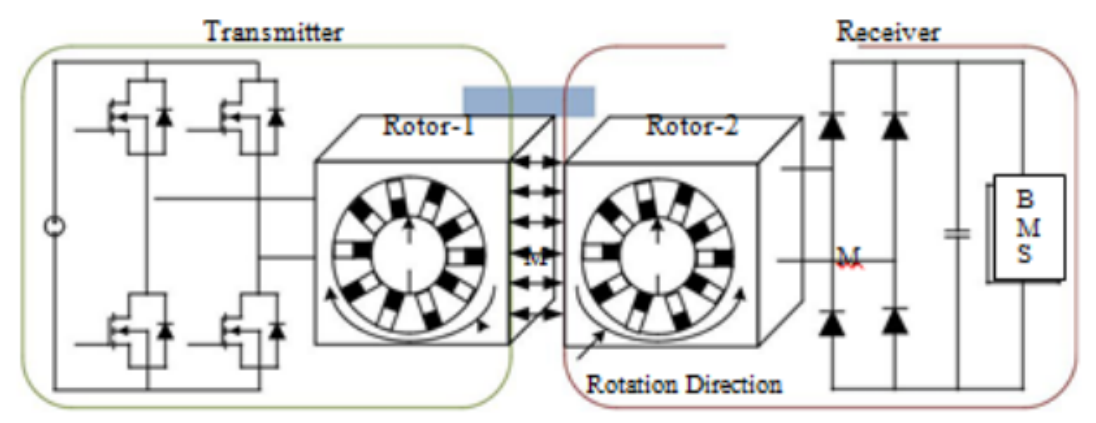

Figure 2 Diagram of MGWPT

\subsubsection{Capacitive wireless power transfer}

This type of technique is quite useful for low power applications, such as portable electronics devices, cellular phone chargers. It uses advanced geometric and mechanical structures of coupling capacitors by virtue of its low cost and simplicity $[9,10]$. A series resonant circuit based CPWT is depicted through a schematic diagram as shown in figure 3 . In this technique, the power is transferred from the source to the receiver, without using coils or magnet, just by coupling capacitors. The main AC voltage is put in to an H-bridge converter which generates high frequency AC. CWPT operates for both low current and high voltage dissimilar to IWPT.

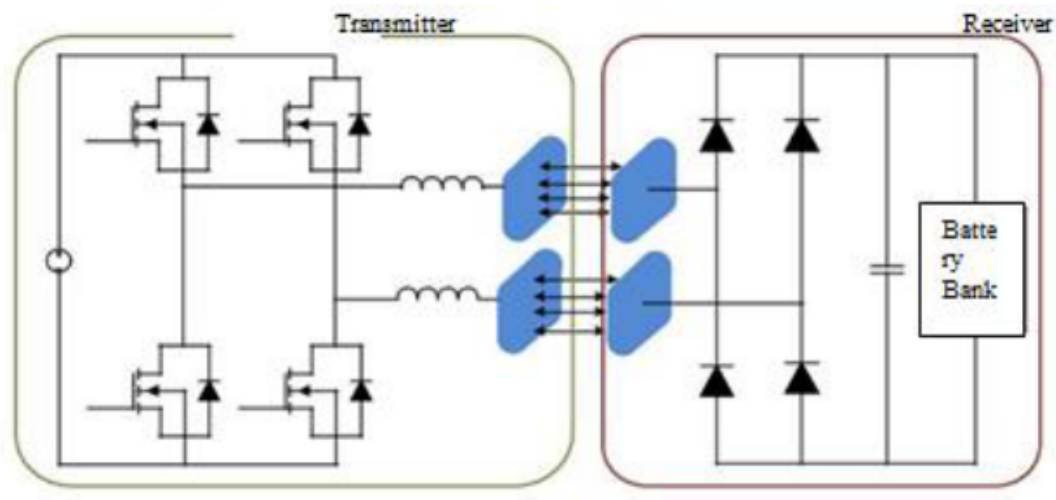

Figure 3 Diagram of CWPT 
In addition to the coupling capacitors few inductors are added in series in order to decrease impedance between the transmitter and receiver. Correspondingly, the received AC voltage is converted to DC for the battery and filter circuitry. The power transfer level depends upon the distance the plates have in between them and the dimensions of coupling capacitors. CWPT proffers high quality performance and improved field constraints are developed between the two plates of the capacitors. Until now, the applications of CWPT for electric vehicles has been restricted due to large air gaps and high-power requirements. A way to reduce the air gap was proposed by authors; by propounding the car's bumper bar as a receiver. A static sample model having power greater than $1 \mathrm{kw}$ was exhibited with around $83 \%$ efficiency from the DC source to the battery at $540 \mathrm{kHz}$ operating frequency.

\subsubsection{Inductive wireless power transfer}

Initially it was invented by Nikola Tesla in the year 1914. The fundamental block diagram of the initial IWPT is illustrated in figure 4. Inductive wireless power transfer has been examined and employed in diversified areas stretching from milliwatts to kilowatts to transfer contactless power from the source to the receiver. Later in the year 1996, Chevrolet S10 was introduced which had a magnet-charge IWPT system for charging. It had two levels: slow $(6.6 \mathrm{~kW})$ and fast $(50 \mathrm{~kW})[8]$. The primary coil was installed into the charging port of the vehicle while the secondary coil received power and permitted to charge the electric vehicle.

\subsubsection{Resonant inductive power transfer}

Resonant inductive power transfer is an advanced version of the inductive wireless power transfer when the designing of power electronics and wireless transformer coils are considered

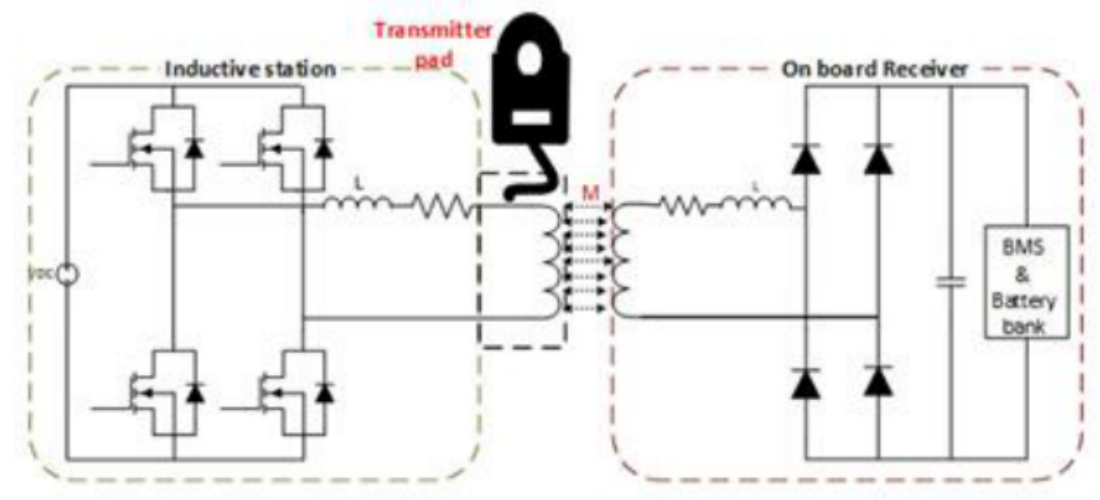

Figure 4 Diagram of IWPT

The basic diagram of RIPT for electric vehicles is illustrated in figure 5. Similar to the other wireless power transfer techniques, high frequency AC is furnished to the transmitter or primary coil. The secondary coil receives power from the varying magnetic fields. In RIPT, additional compensation networks in series and parallel are added to both primary and secondary coils to lessen additional losses.

$$
f_{r(p, s)}=\frac{1}{2 \pi \sqrt{L_{p, s} \cdot C_{p, s}}}
$$

where, $f_{r}$ is the resonant frequency of both the primary and secondary windings, $C$ is the capacitance of primary and secondary windings, $\mathrm{L}$ is the self-inductance of the transmitter and receiver coils. For efficient power transfer, the resonant frequencies of both the windings should match. RIPT can be operated through a wide range of frequencies (from tens of $\mathrm{kHz}$ to hundreds of $\mathrm{kHz}$ ). Coupling coefficient $(\mathrm{k})$ faces a reduction because of the adverse effect on the inductance due to the magnetic flux produced at this frequency span $[11,12]$. 


$$
k=\frac{L_{m}}{\sqrt{L_{p} L_{s}}}
$$

where, $L_{p}$ and $L_{s}$ are the self-inductance of the transmitter and receiver windings respectively, $\mathrm{L}_{m}$ is the mutual inductance between the windings. Due to the minimum height requirement of the electric vehicles of $150-250 \mathrm{~mm}$, $\mathrm{k}$ varies from 0.2 to 0.3 .

Coupling coefficient is made better through the utilization of magnetic ferrite cores in multiple different structures in a wireless transformer design. It will be elaborated in later section of the paper. Working at high frequency can lead to issues such as skin and proximity effects which in turn will affect the power transfer efficiency. This issue can be dealt by considering insulated thin twisted wire-based litz wire in the design. Moreover, it can also lessen the parasitic resistance and ameliorate the quality factor (Q) of the winding.

$$
Q=\frac{\omega \cdot L_{p, s}}{R_{p, s}}=\frac{2 \pi f \cdot L_{p, s}}{R_{p, s}}
$$

where, $\mathrm{f}$ is the frequency, $\mathrm{L}$ is the self-inductance of primary and secondary windings, and $\mathrm{R}$ is the resistance of the windings.

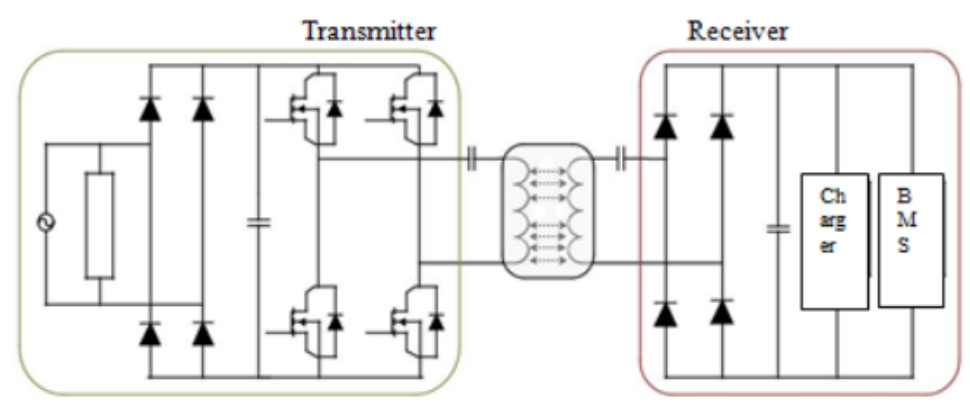

Figure 5 Diagram of RIPT

\subsection{Compensation Network Types}

Compensation networks basically contains capacitors in series and parallel combinations added on both the primary and secondary sides in the WCS for electric vehicles. There are four possible ways to add the compensation capacitor: series-series, parallel-parallel, series-parallel, and parallel-series. All these types of networks are shown in figure 6.

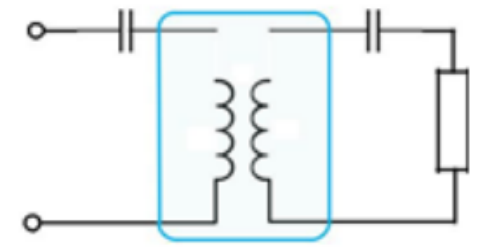

(a)

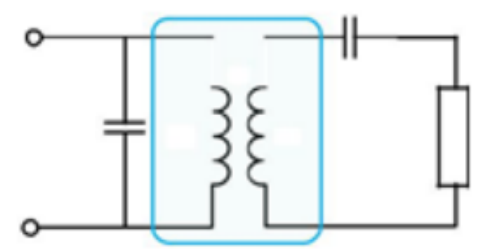

(c)

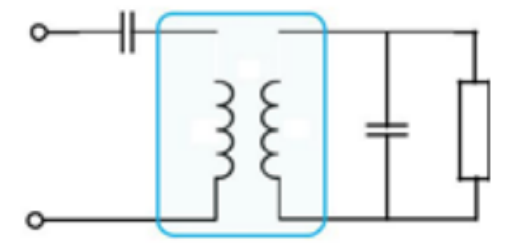

(b)

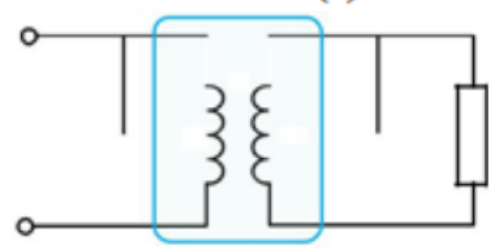

(d)

Figure 6 Compensation networks. a) Series-series b) Series-parallel c) Parallel-series d) Parallelparallel 
For to eradicate the phase difference between the voltage and current, a source compensation is indispensable, which further will also reduce the reactive power in the source $[13,14]$. Selection of the type of compensation network depends on the application demand in the wireless power transfer. Series-series compensated network is best for electric vehicle applications as it provides two important advantages: independency of value of the capacitor from the mutual inductance and load conditions, second is the ability of such systems to maintain a unity power factor by drawing active power at the resonant frequency $[15,16]$. This type can provide a finer battery charging alternative as it may provide a constant current and voltage for the battery $[6,17]$. In order to depict the additional advantages and characteristics of distinct compensation networks in electric vehicles, a table with related content is mentioned below $[6,8,18]$.

Table 1 Additional advantages and characteristics of compensation networks in EVs

\begin{tabular}{|c|c|c|c|c|}
\hline Features & $\begin{array}{c}\text { Series- } \\
\text { Series }\end{array}$ & $\begin{array}{c}\text { Series- } \\
\text { Parallel }\end{array}$ & $\begin{array}{c}\text { Parallel- } \\
\text { Series }\end{array}$ & $\begin{array}{c}\text { Parallel- } \\
\text { Parallel }\end{array}$ \\
\hline Power transfer capacity & High & High & Low & Low \\
\hline Sensitivity of power factor over distance & Less & Less & Moderate & Moderate \\
\hline Alignment Tolerance & High & High & Moderate & Low \\
\hline Impedance at resonant state & Low & Low & High & High \\
\hline Frequency tolerance on efficiency & Low & High & Low & High \\
\hline Suitability for EV applications & High & High & Moderate & Moderate \\
\hline Load & $\frac{\omega . L_{s}}{Q_{s}}$ & $\omega . L_{s} \cdot Q_{s}$ & $\frac{\omega . L_{s}}{Q_{s}}$ & $\omega . L_{s} \cdot Q_{s}$ \\
\hline
\end{tabular}

\subsection{Wireless transformers}

In WCS, in order to attain maximum power transfer efficiency and minimum electromagnetic interference with optimum cost, the receiver and transmitter pads must be made up of multiple component layers. There are three main component layers in the wireless transformer pads: shielding material, coil, and protective layer.

\subsubsection{Coil shapes and their effects}

The main concept used in wireless charging systems for electric vehicles is based on air-core wireless transformer. In figure 7, different types of coil shapes are illustrated which includes rectangular, circular, and hybrids. A particular shape is chosen for the transformer design on the basis of improvement it produces in the performance. Now, these coils are classified into two types: polarized pad and non-polarized pad. The difference between both the pads is that the non-polarized pads produces only vertical component of the flux, while the polarized pads produces both horizontal and vertical components of the flux [19]. Non-polarized pads are the conventional shaped coils, like square, rectangular, hexagonal and circular. Among these, circular coils are popular because in this type of structure eddy currents are maintained to a minimum (no vertices). Magnetic flux distribution can be governed simply by altering internal diameter. Now, for square and rectangular shaped coils, because of their perfectly aligned sides, they are chosen when an array type of arrangement is required. Although, because of the sharp corner edges (vertices), they produce eddy current and eventually increase inductance, impedance and hot spots, which in the end makes them less desirable for high power applications. 
In case of hexagonal shaped coils, maximum power transfer efficiency is achieved at the mid position of the transmitter and receiver coils with a notable decrement as it extends to the edges [20]. Polarized pads came into existence because of the poor performance on the horizontal misalignment plus shapes of PPs are efficient for both 3-phase and 1-phase applications. Few examples of polarized pads are double D, quad D quadrature, double D quadrature, solenoidal coil et cetera. All these types are created by positioning different shaped coils in different orders. For instance, square or rectangular coils makes a double D polarized pad. Likewise, through winding coils all over the flat ferrite plate gives a solenoidal coil. Double $\mathrm{D}$ quadrature coil is an advanced version of the double D polarized pads. Additional improvement in lateral misalignment gives it the edge. Plus, it can act as a secondary pad due to its capability

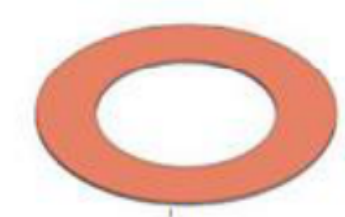

(a)

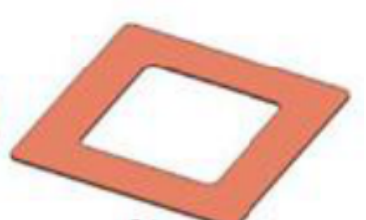

(b)

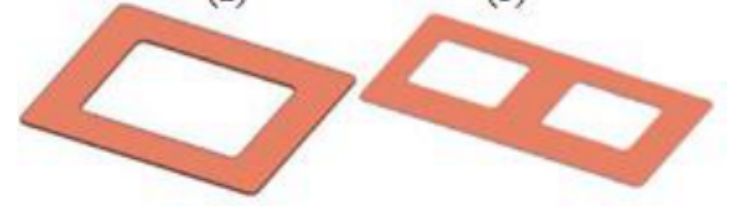

(b)

(d)

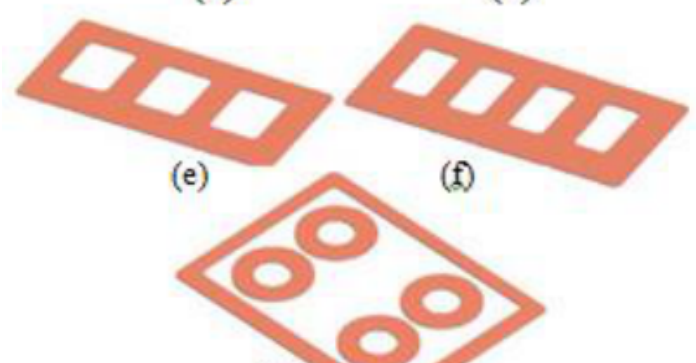

(g)

Figure 7 a) Circular b) Square c) Rectangular d) Double D e) Bi-polar f) Double D Quadrature g) Quad D Quadrature

To seize both sinusoidal and cosine flux vectors. Quad D quadrature pads are made by utilizing two or more circular and square coils. They have been introduced so as to improve the overall performance which involves flux height and misalignment. Comparatively, quad D quadrature provides large value of coupling coefficient (0.35 at $150 \mathrm{~mm}$ air-gap) [7].

\subsubsection{Magnetic ferrite design}

Magnetic ferrite design is important as it affects the coupling efficiency and it also enhances the mutual inductance as well as the self-inductance of the coils [21]. Various factors are considered while designing a ferrite core, such as size, shape, frequency, permeability and cost. Magnetic ferrite shapes like square, rectangular, and circular are used in both the transmitter and receiver to lessen leakage fluxes in wireless charging system for electric vehicles [22]. Although E-core, U-core, and pot ferrite shapes provides higher coupling coefficient, unsuitable for EVs because of their height as electric vehicles have standard ground clearance. ManganeseZinc (high permeability) are used in corresponding applications because of their availability and affordability. 


\subsubsection{Protective and supportive structure}

In wireless electric vehicle charging system, the transmitter pad is placed beneath the surface of road which intend to handle the weight and vibration of an electric vehicle. To provide protection and safety, PVC plastic sheets are used to produce the top and bottom of charging pads. Its dimensions depend on the size and thickness of the charging pad. Sometimes thickness varies from $6 \mathrm{~mm}$ to $21 \mathrm{~mm}$. Occasionally, transparent acrylics are also put on around the coil for support and to intensify the look of the charging pad.

\subsection{Health and safety issues}

Along with the perks of wireless charging systems there comes three important potential health and safety issues namely electrical, magnetic and fire hazards. As WEVCS works in high voltage and current levels, safety concerns become most important. Sometimes it can also produce electrical shocks due to breakdown of devices or physical damage or by environmental conditions. Furthermore, there are two levels of wireless electric vehicle charging systems which are frequently adapted in small places such as houses, dormitories, parking areas, et cetera, where the charging pads are installed beneath the ground. Such arrangements demand some added safety rules and regulations so as evade any possible mishaps. While working at high power levels it is possible for magnetic flux to exceed the minimum value given by the standard authority, in such cases flora and fauna becomes vulnerable and are exposed to a probable danger. To safeguard them, electromagnetic compatibility and electromagnetic interference must be inquired which can resolve the quandary of the safety attributes (this statement is still cryptic).

Table 2 International Society of Automotive Engineers standards for wireless charging in electric vehicles

\begin{tabular}{|c|c|c|c|c|}
\hline Features & \multicolumn{3}{|c|}{ Wireless power transfer levels } \\
\hline \multirow{2}{*}{ Maximum input power $(\mathrm{kW})$} & WPT-1 & WPT-2 & WPT-3 & WPT-4 \\
& 3.7 & 7.7 & 11 & 22 \\
\hline Minimum Target efficiency & \multicolumn{4}{|c|}{85 (Band: 81.39-90) } \\
\hline Operating frequency $(\mathrm{kHz})$ & \multicolumn{4}{|c|}{} \\
\hline
\end{tabular}

Since there is a high-power transfer from the transmitter to the receiver charging pads at substantially big air gap of about 150 to $300 \mathrm{~mm}$, the extent of high frequency leakage flux produced increases. There is a pre-defined permissible flux value which must not be exceeded considering human body [23]. Exposure of these leakage fluxes may harm a person while sitting inside the vehicle or even strolling near a charging pad. The consequence of electromagnetic compatibility and electromagnetic interference problems had to be substantiated; to achieve the solution set a variety of different shapes of magnetic ferrite are propounded with finite element method (FEM) simulation [21,24]. Moreover, numerous research and development projects are in progress to achieve a user friendly WEVCS. In conclusion, while defining safety and health standards one must consider design, construction, manufacturing and installation for to produce user friendly harmless wireless electric vehicle charging system.

\section{APPLICATIONS OF WEVCS}

\subsection{Static WEVCS}

In static WEVCS, there is zero driver participation in charging system which reduces chances of mishaps or current shocks or any sort of hazard. In this system, the transmitter is beneath the 
concrete of the parking area and the receiver is placed on the bottom of the electric vehicle's bumper with both having power converters and some circuits. Behind the power converter of the receiver coil an energy storage device is there which is also called here as battery bank. Battery management system and power control are inclusive in the safety management module so as to circumvent any possible mishaps. This type of WEVCS can be stationed at home fronts, parking spots, commercial spots, and shopping center's parking area. Few testing models have been developed by various research centers, universities (table 3 illustrates it all) $[1,8,12,25,26]$. Cost of the charging pads depends upon the power levels: level $1(3.3 \mathrm{~kW})$, level $2(7.2 \mathrm{~kW})$. It ranges from $2600 \$$ to $14000 \$$. Additionally, the WEVCS power levels must satisfy the standards set by international society of automotive engineers and moreover, they are working on the permissible misalignment and installation environment of the receiver pad in the electric vehicle.

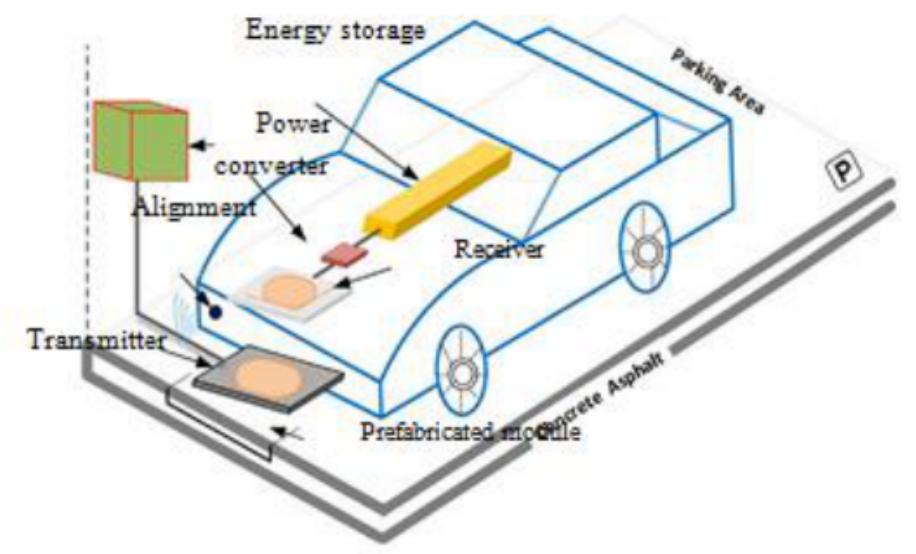

Figure 8. Diagram of Static WEVCS

Table 3 Development statistics of static WEVCS

\begin{tabular}{|c|c|c|c|c|c|}
\hline R \& D Institution & Vehicle Type & $\begin{array}{c}\text { Air-Gap } \\
(\mathbf{m m})\end{array}$ & $\begin{array}{c}\text { Operating } \\
\text { Frequency } \\
(\mathbf{k H z})\end{array}$ & $\begin{array}{c}\text { Power } \\
\text { Range } \\
(\mathbf{k W})\end{array}$ & $\begin{array}{c}\text { Efficiency } \\
(\%)\end{array}$ \\
\hline \multicolumn{6}{|c|}{ Companies and Start up Organizations } \\
\hline \multirow{3}{*}{$\begin{array}{l}\text { Plug-less Power } \\
\text { (Evatron Group) }\end{array}$} & \multirow{3}{*}{ Passenger Car } & \multirow{3}{*}{100} & \multirow{3}{*}{25} & 3.3 & \multirow{3}{*}{89} \\
\hline & & & & 3.6 & \\
\hline & & & & 7.2 & \\
\hline \multirow{3}{*}{ Witricy Corporation } & \multirow{3}{*}{$\begin{array}{c}\text { Passenger Car } \\
\text { and SUVs }\end{array}$} & \multirow{3}{*}{$110-260$} & \multirow{3}{*}{86} & 3.5 & \multirow{3}{*}{$>89$} \\
\hline & & & & 7.6 & \\
\hline & & & & 12 & \\
\hline \multirow{3}{*}{ Qualcom Halo } & \multirow{3}{*}{ Sports Car } & \multirow{3}{*}{$150-210$} & \multirow{3}{*}{86} & 3.5 & \multirow{3}{*}{$>89$} \\
\hline & & & & 6.7 & \\
\hline & & & & 7 & \\
\hline Siemens and BMW & Passenger Car & $90-160$ & $\begin{array}{c}\text { Not } \\
\text { Announced }\end{array}$ & 3.5 & $>89$ \\
\hline
\end{tabular}


Charging System Analysis in Static and Dynamic Wireless Electric Vehicle

\begin{tabular}{|c|c|c|c|c|c|}
\hline \multicolumn{7}{|c|}{ Universities and research centers } \\
\hline $\begin{array}{c}\text { Michigan state } \\
\text { university }\end{array}$ & $\begin{array}{c}\text { Laboratory } \\
\text { Experiment }\end{array}$ & 210 & 65 & 1.1 & $\sim 80$ \\
\hline University of Auckland & Passenger Car & $110-310$ & 35 & 4 & $>84$ \\
\hline $\begin{array}{c}\text { Korea Institute of } \\
\text { Technology }\end{array}$ & $\begin{array}{c}\text { Laboratory } \\
\text { Experiment }\end{array}$ & 160 & 88 & 4.2 & 91 \\
\hline $\begin{array}{c}\text { Oak Ridge National } \\
\text { Laboratory }\end{array}$ & $\begin{array}{c}\text { Laboratory } \\
\text { Experiment }\end{array}$ & $110-170$ & 19.6 & 6.6 & $88-89$ \\
\hline
\end{tabular}

\subsection{Dynamic WEVCS}

Range and cost are the setbacks plug-in charging systems are facing currently. As to increase the range it is essential to charge electric vehicles very often or maybe put a larger battery bank, all of which comes with an increased undesirable weight and cost. Against these compelling challenges, dynamic wireless electric vehicles charging system comes to its aid. Basically, this will lessen the issues corresponding to range and cost. Sometimes, DWEVCS is also known as in-line WEVCS or roadway powered WEVCS [27]. In this type of charging system, the transmitter is placed beneath the concrete of the road all along the pathway with high frequency $\mathrm{AC}$ and circuitry and the receiver below the front of the vehicle as it was in static WEVCS with power converter and battery management system which converts high frequency AC into DC and then powers up the battery bank. In comparison with the other one, DWEVCS reduces the battery consumption by $19 \%$ [28].

In a bigger scenario, as future holds the self-driving cars, it is efficient and practical for the transmitter unit to be aligned beneath the concrete in a pre-defined route. Initial

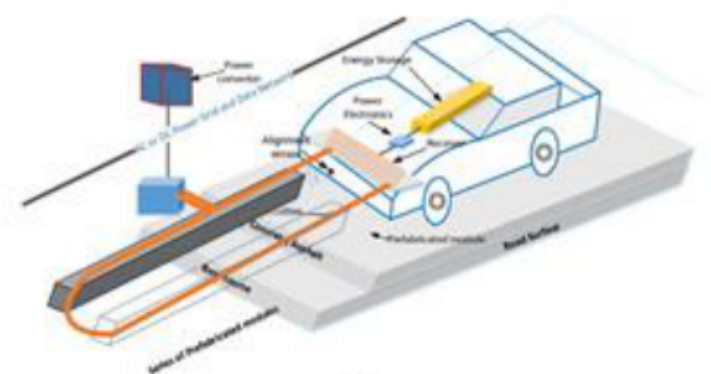

(a)

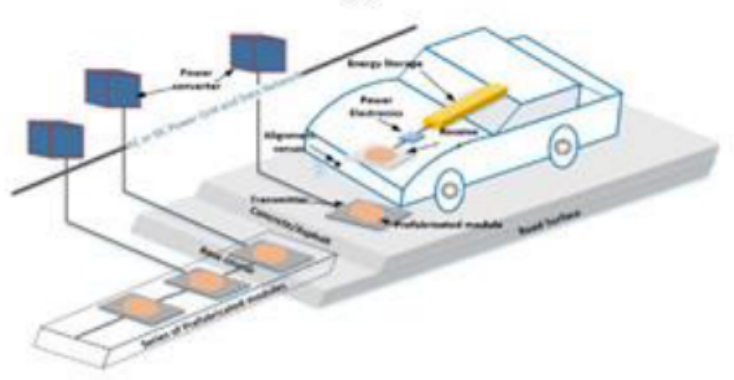

(b)

Figure 9 Elementary diagram of Dynamic WEVCS

cost of the whole project is high but seeing in a broader prospect it is the best option for such technology. This technology ameliorates the total power transfer efficiency in EVs. In 
addition, it is easy to incorporate even in electric bus, rail and rapid rail. In order to understand the evolution of dynamic wireless electric vehicle charging systems, below is the table with all the necessary facts and information as far as development is concerned.

Table 4 Development statistics of Dynamic WEVCS

\begin{tabular}{|c|c|c|c|c|}
\hline R \& D Institutions & $\begin{array}{c}\text { Pick-up Power } \\
\mathbf{( k W )}\end{array}$ & $\begin{array}{c}\text { Operating } \\
\text { Frequency } \\
\mathbf{( k H z )}\end{array}$ & $\begin{array}{c}\text { Air-Gap } \\
\mathbf{( m m )}\end{array}$ & $\begin{array}{c}\text { Efficiency } \\
\mathbf{( \% )}\end{array}$ \\
\hline University od Auckland & $21-30$ & 13 & 450 & 84 \\
\hline $\begin{array}{c}\text { Japan Railway Technical } \\
\text { Research Center }\end{array}$ & 55 & 11 & 7.7 & 85 \\
\hline Oak Ridge National Lab. & 21 & 23 & $130-180$ & 89 \\
\hline Nissan Research Center & 1.1 & 89 & 110 & $>89$ \\
\hline Flanders Drive & 84 & 21 & 110 & $87-89$ \\
\hline
\end{tabular}

\section{FUTURE APPLICATIONS}

\subsection{Wireless vehicle to grid (W-V2G)}

The increasing adaptation of plug-in electric vehicles has increased the energy requirement. In order to compensate the demand auxiliary power supply is required which is fulfilled by renewable energy sources (RES) but they have scanty support amenities. Apace with the improved scheduling for charging and discharging the distribution network, the vehicle to grid abstract can prose an improvised outcome demonstrating the bi-directional power transfer application for plug-in electric vehicles inclusive of both plug-in mode and wireless mode [8]. Plug-in V2G involves electric vehicles with on-board bi-directional charger to permit the user to switch between the home and the grid network throughout the peak hours. The vehicle is charged using an AC socket when used during the non-rush hours. To produce the DC source, the $\mathrm{AC}$ is converted to DC and is given to a DC converter unit so as to ensure safety of the user. The converted direct current is supplied to a battery via BMS, protection and control and a multi directional DC converter. When the battery bank needs to be charged, this bi-directional DC converter operates in step down mode and in the process to increase the power level while discharging, it boosts up to ensure optimum power supply.

The drawback involving in this process is that it demands a direct contact and physical handling to ensure that charging and discharging takes place in the electric vehicles. The manual and physical contact demands additional safety measures to be taken to avoid accidents involving electric shocks and trip risk. To avoid these situations, a wireless V2G network is being processed. The differences between the wireless and the plug-in V2G are illustrated in table 7. The primary side of the transformer is installed on the road or the parking zone with bidirectional power converters which are not present in the plug-in V2G. the receiver coil is embedded underneath the vehicle and the remaining bi-directional power converting units are placed inside the vehicles body. The device is completely self-governing and provides extra confinement between the receiver side and the source through the wireless transformer. The proposed model facilitates excess energy to be transferred to the plug-in electric vehicles to curtail stress or accept energy to correct high demand energy in fixed and dynamic modes. Moreover, this proposed model can be used as a substitute for mobile energy storage in the ever changing V2G operation. 


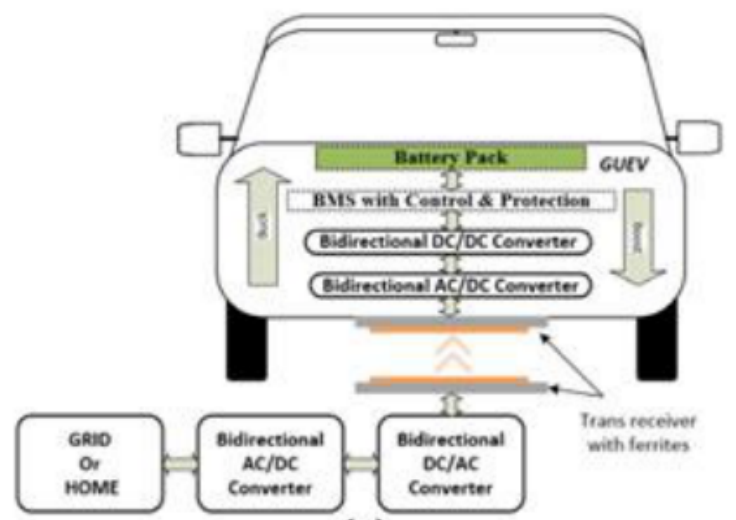

(a)

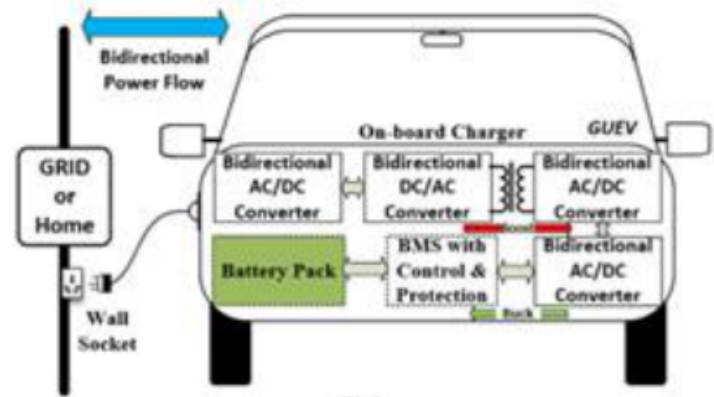

(b)

Figure 10 a) W-V2G b) Plug-in V2G

Table 5 Differences between Wireless and Plug-in V2G

\begin{tabular}{|c|c|c|}
\hline Features & Wireless V2G & Plug-in V2G \\
\hline Method & Wireless power transfer Traditional Conductive \\
\hline Operating frequency & $82-89 \mathrm{kHz}$ & $18-102 \mathrm{kHz}$ \\
\hline Air-gap sensitivity & Moderate to high & N/A \\
\hline Position sensitivity & Moderate to high & N/A \\
\hline Power transfer efficiency & $>89 \%$ & $>89 \%$ \\
\hline Electric shock Hazard & Low to Moderate & Moderate to high \\
\hline Suitability & Very high & Moderate \\
\hline
\end{tabular}

\subsection{In wheel wireless charging system}

\subsubsection{Configuration of in wheel wireless charging system}

Both the static and dynamic wireless charging systems are facing challenges; the most crucial challenge is the power transfer efficiency, affected due to air gap. Air gap here is the gap between the transmitter and the receiver coils which can vary according to the type of vehicle, larger for heavy vehicles smaller for light duty passenger vehicles [9,29]. Another important factor on which the power transfer efficiency depends is the coil alignment which can be improved by using the parking assistance to find the center of the coil. Further to ameliorate the air gap issues in electric vehicles, in wheel wireless charging system has been introduced for both static and dynamic applications. The future technologies in wireless charging are inclusive 
of static and dynamic IW-WCS in both electric and hybrid electric vehicles. The transmitter is located similarly as in the other WEVCS, but the receiver coil is placed into the tyre structure which eventually reduces the air-gap and increases coupling efficiency for more effective power transfer. In order to obtain an efficient static and dynamic IW-WCS three components must be designed carefully namely wireless transformer, power source, and internal structure of tyre. Numerous receiver coils are mounted in parallel combinations in the interior of tyre, so at a time only one coil which is in the contact of the transmitter gets activated. Specifications of both the coils used in "in wheel wireless electric vehicle charging system" are illustrated in table 8 .

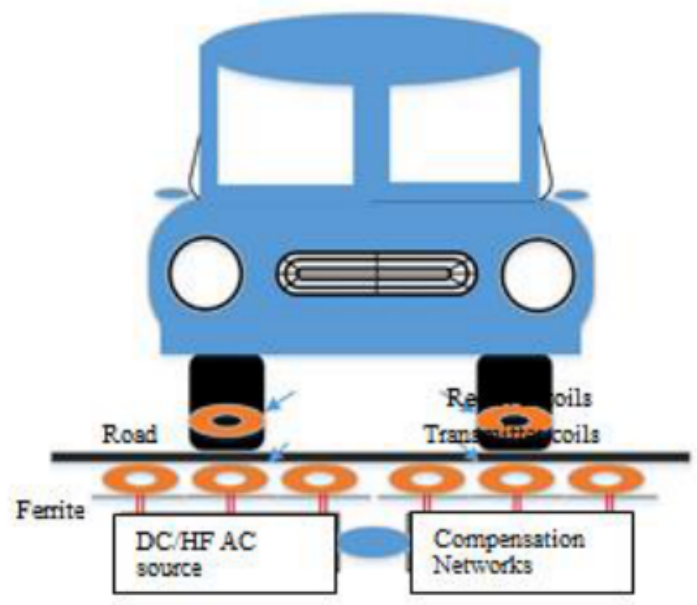

Figure 11 Diagram of in-wheel wireless charging system

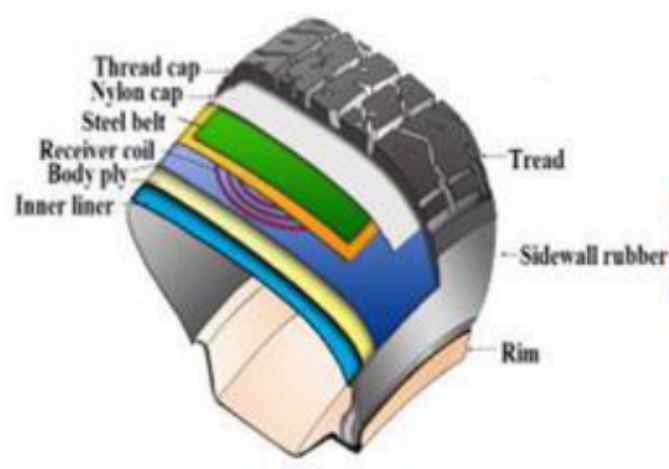

(a)

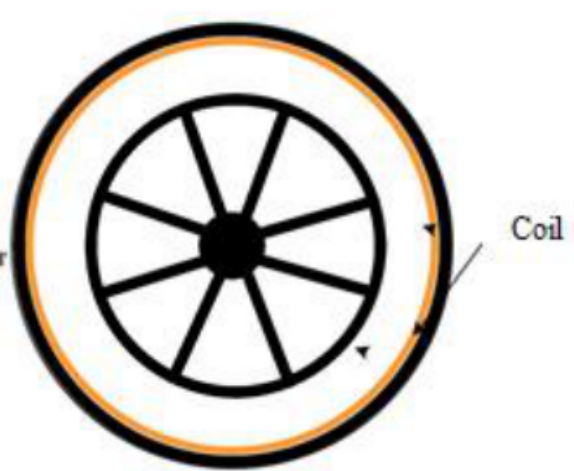

(b)

Figure 12 a) Internal coil arrangement b) Coil placement

\subsubsection{Computational evaluation}

Finite element method simulation was implemented in order to observe and learn the magnetic field distribution in both stationary and dynamic in-wheel wireless charging system. For the simulation, a $10 \mathrm{~mm}$ broad incorporated steel belt rubber tyre with $7 \mathrm{~mm}$ air gap (in-wheel) and $17 \mathrm{~mm}$ air gap in primary and secondary windings (via-wheel) were considered as models. While dealing with high frequency the MFD and the current density of the primary coils with the ferrite cores was generated where the magnetic permeability of the tyre was selected as it has identical permeability as of air in the presence of magnetic field. The incorporated steel 
pulls certain amount of magnetic flux towards it which in-turn results in an increment in the leakage of magnetic flux associated with the transformer. Plus, coupling coefficient (k) takes a decline from 0.50 to 0.44 because of mutual inductance. Furthermore, another simulation was done which had an aluminum rim inside the tyre at $45 \mathrm{~mm}$ distance from the secondary winding as the prototype to clear the aftermath of the rim. Through the results, it can be seen that the aluminum rim helps in lessening the leakage flux and enhancing the coupling coefficient. Finally, it can be said that it assists in reducing the possibility of any sort of hazard or mishap related to the wireless electric vehicle charging system.

\subsubsection{In-wheel WCS vs Via-wheel WCS}

Both have significant advantages and disadvantages and few limitations as well but to decide which one's better and efficient for now and for future we need to compare them based on few important attributes and characteristics. Via-wheel wireless charging systems used to transfer power by employing CWPT method while the in-wheel wireless charging systems employs the RIPT method. This change in technique is advantageous because of the high sensitivity of coupling efficiency with respect to the distance between the coils in CPWT as compared to RIPT technique. Furthermore, using CPWT method could get dangerous and harmful for human race due to the range of its operating frequency which falls under radio range (51-56 $\mathrm{MHz}$ ) which is not the case in RIPT as it functions in 91-100 kHz range. To summarize it can be said that in-wheel wireless charging systems are much likely to be more productive. A complete qualitative comparison of futuristic in-wheel wireless charging system and the already existing via-wheel wireless charging system is illustrated in table 9 below.

Table 6 Qualitative Comparison of futuristic in-wheel WCS and the existing via-wheel WCS

\begin{tabular}{|c|c|c|}
\hline Features & In-wheel WCS & Via-wheel WCS \\
\hline Method & Resonant Inductive power transfer & Capacitive power transfer \\
\hline Wireless Transformer & Coils & Steel belt \\
\hline Coupling efficiency & High & Moderate to high \\
\hline Air gap sensitivity & Low to moderate & High \\
\hline Position & Horizontal & Vertical \\
\hline Operating frequency & $110 \mathrm{kHz}$ & $51-56 \mathrm{MHz}$ \\
\hline Total power transfer & $110 \mathrm{~W}$ & $65 \mathrm{~W}$ \\
\hline Power transfer efficiency & $>81 \%$ & $71-79 \%$ \\
\hline Health and safety & Capable of high-power transfer & Limited due to tyre safety \\
\hline
\end{tabular}



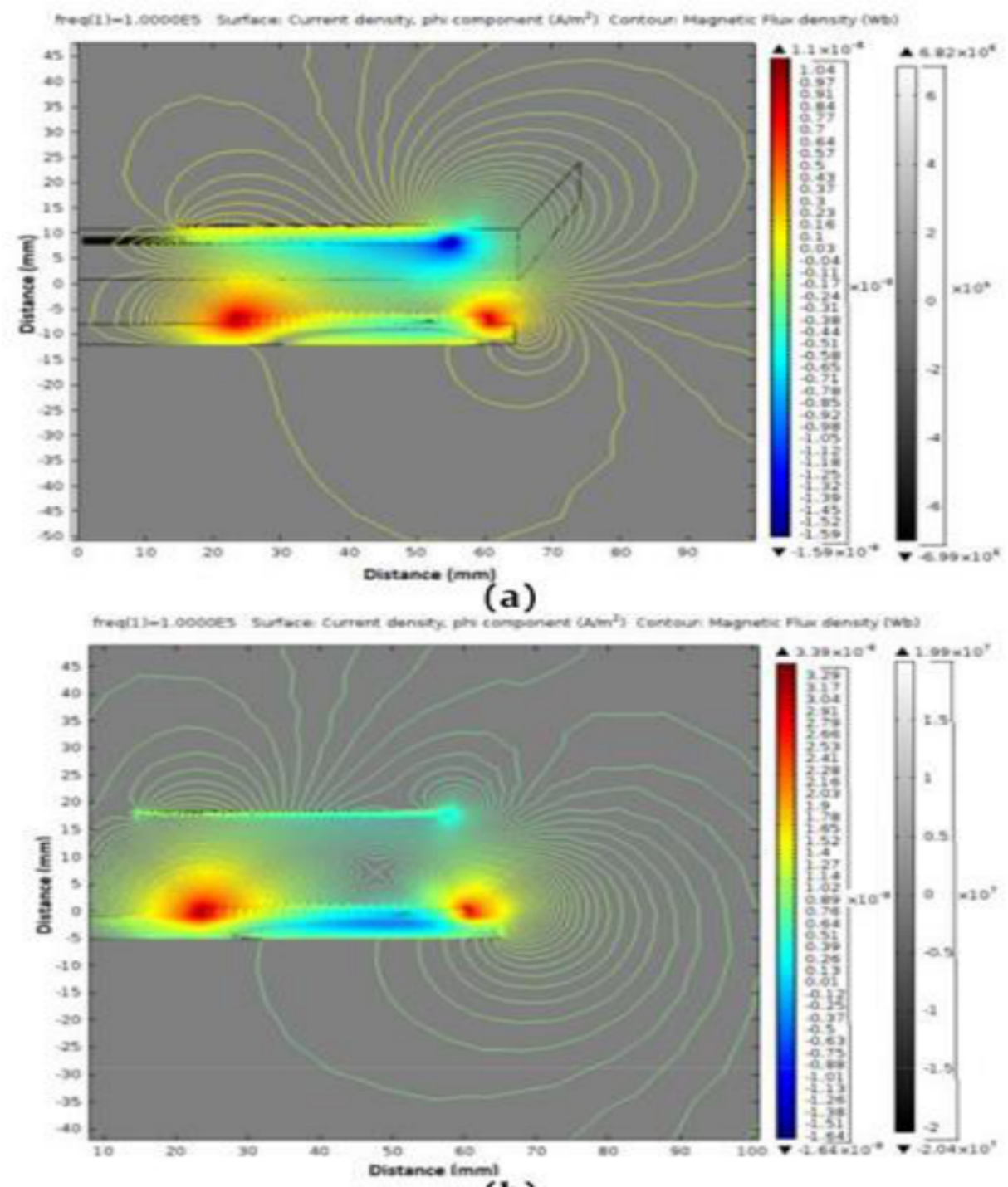

(b)

Figure 13 Results of simulation a) $10 \mathrm{~mm}$ broad incorporated steel belt rubber tyre with $7 \mathrm{~mm}$ air gap b) $17 \mathrm{~mm}$ air gap in primary and secondary windings (via-wheel)

\section{CONCLUSION}

In conclusion, the research paper contains a fundamental review of the WEVCS for static and dynamic applications with present day technology. Besides, it also discusses and exemplifies different kinds of core and ferrite shapes with the introduction of variety of design of wireless charging pads. Moreover, health issues and safety problems have been addressed in order to avoid mishaps and hazards which are important for the evolution of WEVCS in EVs. Facts and information from research and development departments of several universities, private institutions are investigated, recorded and tabled in this paper. Lastly, it contains the detailed description of the future technologies with the results of simulation using finite element method (FEM). Overall, the evolution in the field of wireless electric vehicle charging systems is illustrated in this study. 
Charging System Analysis in Static and Dynamic Wireless Electric Vehicle

\section{REFERENCES}

[1] Kalwar, K.A., Amir, M., Mekhilef, S., Renewable Sustainable Energy Rev., 47, 2015, pp. $462-$ 475.

[2] Ombach, G., Hybrid Electric Vehicles Conference, 2013, pp. 1-4.

[3] Lukic, S., Pantic, Z., Electr. Magazine, IEEE 1, 2013, pp.57-64.

[4] Zhu, Q., Wang, L., Liao, C., IEEE Trans. 1, 2014, pp. 42-54.

[5] Jinwook, K., Do-Hyeon, K., Young-Jin, P., IEEE Trans., 62, 2015, pp. 2807-2813.

[6] Villa, J.L., Sallan, J., Osorio, J.F.S., Llombert, A., IEEE Trans. Indust. Electr., 59, 2012, pp. 945-951.

[7] Kalwar, K., Mekhilef, S., Seyedmahmoudian, M., Horan, B., Energies, 9, 2016, pp. 937.

[8] Leskarac, D., Panchal, C., Stegen, S., Lu, J., The Institution of Engineering and Technology (IET), London, 2015, pp. 157-209.

[9] Liu, C., Wang, B., Nair, N.K.C., IEEE Trans. Indust. Electr., 60, 2013, pp. 249-260.

[10] Dai, J., Ludois, D.C., IEEE (APEC), 2015, pp. 3307-3313.

[11] Panchal, C., Lu, J., Stegen, S., International Journal of Science and Technology, 6, 2017, pp. 280-284.

[12] Vilathgamuwa, D.M., Sampath, J.P.K., Springer International Publishing AG, Part of Springer Science+Business Media, Springer Singapore, 2015, pp.33-60.

[13] Li, S., Mi, C., IEEE J., 1, 2014, pp. 4-10

[14] Sabki, S.A., Tan, N.M.L., IEEE International Power Enigneering and Optimization Conference, 8, 2014, pp. 41-46.

[15] Chinthavali, M., Zhiqiang, W., Campbell, S., IEEE Trans. Electr. Conf. Expo, 2016, pp. 1-8.

[16] Spanik, P., Frivaldsky, M., Jaros, V., ELEKTRO, 2016, pp. 231-237

[17] Tung, H.Y., Lai, L.L., Ko, K.T., Lam, K.L., IEEE International Conference, 2011, pp. 507-508.

[18] Duan, S., Chen, C., Cai, T., Zhao, J., IEEE Trans. Power Electron, 31, 2016, pp. 8343-8358.

[19] Aditya, K., Williamson, S., Sood, V., IEEE Trans, 2017.

[20] Lee, C., Shan, Z., Chen, W., Energies, 9, 2016, pp. 906.

[21] Lu, J., Panchal, C., Stegen, S., IEEE PES Asia-Pacific, 2015, pp. 1-5.

[22] Leskarac, D., Stegen, S., Panchal, C., Lu, J., APEMC Melbourne, Australia, 2013, pp. 380-383.

[23] Bashirullah, R., IEEE Microwave Mag., 11, 2010, pp. 14-23.

[24] Stegen, S., Leskarac, D., Panchal, C., Lu, J., Asia-Pacific Conference (CEEM), 6, 2012, pp. 301-304. 
Sankalp Bhatnagar, Shubham Parihar, Rohan Nathiya and Nikhil Mundra

[25] Mi, C.C., Li, S., IEEE J., 3, 2015, pp. 4-17.

[26] Kwak, B., Kim, M., Choi, Y., IEEE International Conference of Power System and Technology, 2016, pp. 1-3.

[27] Buja, G., Rim, C.T., Mi, C.C., Choi, S.Y., IEEE Trans. Ind. Electron, 63, 2016, pp. 6533-6545.

[28] Edington, M., Musavi, F., Eberle, W., IEEE (ECCE), 2012, pp. 1804-1810.

[29] Li, H.L., Hu, A.P., Liu, C., International Conference on Mechatronics and Machine Vision in Practice, 15, 2008, pp. 646-650.

[30] Dipak A. Mhaske and Prof. S.S. Katariya, Review Wireless Electric Energy Transmission Through Resonance or Magnetic Coupling (Witricity), International Journal of Electrical Engineering and Technology (IJEET), Volume 3, Issue 3, October - December (2012), pp. 4351.

[31] Amruta Gaikwad and Ankit Chourasia, Wireless Electricity (Witricity). Journal of Electrical Engineering \& Technology, 2(1), 2016, pp. 01-07. 